\title{
Anthropogenic influence on the distribution, abundance and diversity of sandfly species (Diptera: Phlebotominae: Psychodidae), vectors of cutaneous leishmaniasis in Panama
}

\author{
Anayansi Valderrama ${ }^{1,3} /{ }^{+}$, Mara Garcia Tavares ${ }^{1}$, José Dilermando Andrade Filho² \\ ${ }^{1}$ Departamento de Biologia Geral, Universidade Federal de Viçosa, Av. Peter Henry Rolfs s/n, 36570-000 Viçosa, MG, Brasil \\ ${ }^{2}$ Centro de Referência Nacional e Internacional para Flebotomíneos/Coleção de Flebotomíneos, Instituto René Rachou-Fiocruz, \\ Belo Horizonte, MG, Brasil ${ }^{3}$ Instituto Conmemorativo Gorgas de Estudios de la Salud, Panama, Panama
}

In Panama, species of the genus Lutzomyia are vectors of American cutaneous leishmaniasis (ACL). There is no recent ecological information that may be used to develop tools for the control of this disease. Thus, the goal of this study was to determine the composition, distribution and diversity of Lutzomyia species that serve as vectors of ACL. Sandfly sampling was conducted in forests, fragmented forests and rural environments, in locations with records of $A C L$. Lutzomyia gomezi, Lutzomyia panamensis and Lutzomyia trapidoi were the most widely distributed and prevalent species. Analysis of each sampling point showed that the species abundance and diversity were greatest at points located in the fragmented forest landscape. However, when the samples were grouped according to the landscape characteristics of the locations, there was a greater diversity of species in the rural environment locations. The Kruskal Wallis analysis of species abundance found that Lu. gomezi and Lu. trapidoi were associated with fragmented environments, while Lu. panamensis, Lutzomyia olmeca bicolor and Lutzomyia ylephiletor were associated with forested environments. Therefore, we suggest that human activity influences the distribution, composition and diversity of the vector species responsible for leishmaniasis in Panama.

Key words: phlebotomines - leishmaniasis - deforestation - ecology - species distribution

Leishmaniasis in Panama was first recorded in 1910. The staff of the Gorgas Memorial Laboratory has researched the ecology and epidemiology of leishmaniasis since that time. Cutaneous leishmaniasis is the most common form of leishmaniasis reported in the Republic of Panama; its clinical manifestations range from minor lesions to severe skin ulcers (Christensen et al. 1972, 1983, 1984). In humans, the disease is mainly caused by Leishmania panamensis, with a distribution extending from Belize-Argentina (Young \& Duncan 1994, Miranda et al. 2009). However, other species such as Leishmania colombiensis, Leishmania mexicana, Leishmania amazonensis and Leishmania braziliensis have been reported; Leishmania aristidesi and Leishmania hertigi have both been isolated from mammals (Herrer 1971, Herrer et al. 1971, Christensen et al. 1972). Another strain, Leishmania naiffi, has recently been found in populations of Lutzomyia gomezi and Lutzomyia trapi$d o i$, but it has not been found in human infections and its reservoirs remain unidentified (Azpurua et al. 2010).

Leishmaniasis is a primarily zoonotic disease. The sloth Choloepus hoffmanni is the primary reservoir of the parasite, but other wild mammals, such as Brady-

Financial support: SENACYT COL09-008

+Corresponding author: anayvald@yahoo.com

Received 3 July 2011

Accepted 17 October 2011 pus variegatus, Saguinus geoffroyi, Nasua nasua, Potos flavus, Bassaricyon gabbi, Proechimys semispinosus, Hoplomys gymnurus and Coendou rothschildi, have also been identified as reservoirs and their role as secondary hosts has been established (Christensen et al. 1984, Méndez 1999).

Phlebotomine sandflies are the vectors of leishmaniasis and are present in almost every country in tropical and subtropical regions. Central and South America have the greatest concentration of these vectors (Young \& Arias 1992, Seccombe et al. 1993, Young \& Duncan 1994). About 74 species of sandflies have been reported in Panama (Christensen 1972, Herrer \& Christensen 1976), including Lutzomyia ylephiletor, Lutzomyia sanguinaria, Lutzomyia panamensis, Lu. trapidoi, Lu. gomezi and Lutzomyia olmeca bicolor. These species were identified as the transmission vectors of the American cutaneous leishmaniasis (ACL) agent in Panama in the 1950s when L. braziliensis sensu lato was isolated from the vectors' digestive tracts (Herrer et al. 1971, Tesh et al. 1971, Herrer \& Christensen 1973).

The distribution of phlebotomine sandflies in Panama correlates with the occurrence of ACL in the endemic regions of the provinces of Bocas de Toro, Veraguas, Coclé, Colón, Panama East, Panama West (MINSA 2005), especially in forest areas. Phlebotomine sandflies develop in humid locations, such as nests, rock crevices, animal burrows and tree bark (Christensen et al. 1983). However, with the depletion of forest and the disappearance of their natural habitat, some species seem to have adapted to degraded habitats, contributing to the spread of ACL (Jiménez et al. 2000, Travi et al. 2002). 
Few recent studies have appeared on the diversity, geographical distribution and abundance of the different species of phlebotomine sandflies as vectors of leishmaniasis agents in Panama. Thus, the aims of the present study were to determine the composition, geographical distribution and diversity of ACL vectors in the endemic regions of Panama. Additionally, this study sought to verify the association between the characteristics of the areas studied and the communities of phlebotomine sandflies inhabiting them.

\section{MATERIALS AND METHODS}

Study area - Sandflies were captured in Panama between the coordinates $7^{\circ} 11^{\prime}-9^{\circ} 39^{\prime} \mathrm{N}$ and $77^{\circ} 10^{\prime}-$ $83^{\circ} 03^{\prime} \mathrm{W}$. The most prevalent climatic regime in $\mathrm{Pa}-$ nama is tropical humid, with the summer season (January-March) presenting an average temperature of $30^{\circ} \mathrm{C}$ and relative humidity of $75 \%$. In other months (AprilDecember), the average temperature is $27^{\circ} \mathrm{C}$ and the relative humidity averages $90 \%$.

There are three different regions in Panama: the Atlantic region, where it rains all year long and there is no clearly defined dry season, the Pacific region, characterised by moderate to heavy rainfall and a well defined dry season, and the central region, that occupies most of the continental part of the country and is subjected to moderate to heavy rains and strong winds due to the thermal contrast between the other two regions.

The vegetation in Panama varies according to the climate zones and consists mainly of tropical humid forest or savannahs resulting from agricultural activity (ANAM 2000). The data on temperature, precipitation and humidity from 2007-2010 were obtained from the weather stations of the Empresa de Transmisión Eléctrica Panameña, located at different points in the country.

This study was conducted at 43 locations throughout eight regions or provinces of Panama (Fig. 1). The landscapes of the locations were heterogeneous with a variety of diverse macro habitats created by human activity. Each site was classified according to its landscape characteristics as one of the following: (i) forest environment, an extension of land with abundant primary or secondary vegetation (flora, fauna and climatic conditions typical of tropical rainforest), (ii) fragmented forest environment, areas degraded by human activity (timber extraction, cattle farming, agriculture etc.), presenting small patches of secondary vegetation close to the degraded areas, or (iii) rural environment, a province or settlement without any great concentration of people or commercial activity, limited urban growth and area used for agriculture. The traps were distributed at specific collection points in each landscape. In the fragmentary forest and rural landscapes, the traps where placed in houses that lacked window covering were in close proximity to domestic animals and ornamental vegetation. For each forest locality, the traps were placed near rock crevices and tree bark.

Sandflies were collected during six months in 2010, January-April (dry season) and May-June (early rainy season) at 43 locations where human cases of ACL had been recorded from 2006-2009, according to the Epidemiology Department of the Ministerio de Salud de Panama.

Adult sandflies were collected using CDC light traps (Sudia \& Chamberlain 1962) and octanol solution (used to attract haematophagous insects) exposed at a height of $1.5 \mathrm{~m}$. At least nine light traps were installed in each locality at approximately $50-\mathrm{m}$ intervals. The collection period was $12 \mathrm{~h}(06: 00 \mathrm{pm}-06: 00 \mathrm{am})$ for two consecutive days. The specimens were sacrificed with chloroform and stored in $95 \%$ ethanol at $-20^{\circ} \mathrm{C}$.

Identification of the collected specimens - Sandflies were classified according to the methods of Young and Duncan (1994). The nomenclature of the subgenus Psychodopygus described by Carvalho et al. (2006) was used in this study.

Analysis - The total abundance $(\mathrm{Pi})(=\mathrm{ni} / \mathrm{N})$ and diversity $\left(\mathrm{H}^{\prime}\right)(=-$ Lpilnpi) of sandfly species at each site was calculated in accordance with the methods described by Magurran (1988). To test the differences in sandfly species abundance at each type of landscape, the Kruskal Wallis test was used $(\mathrm{p} \leq 0.05)$ in conjunction with the multiple comparison test $(\alpha=0.05)$. Explora-

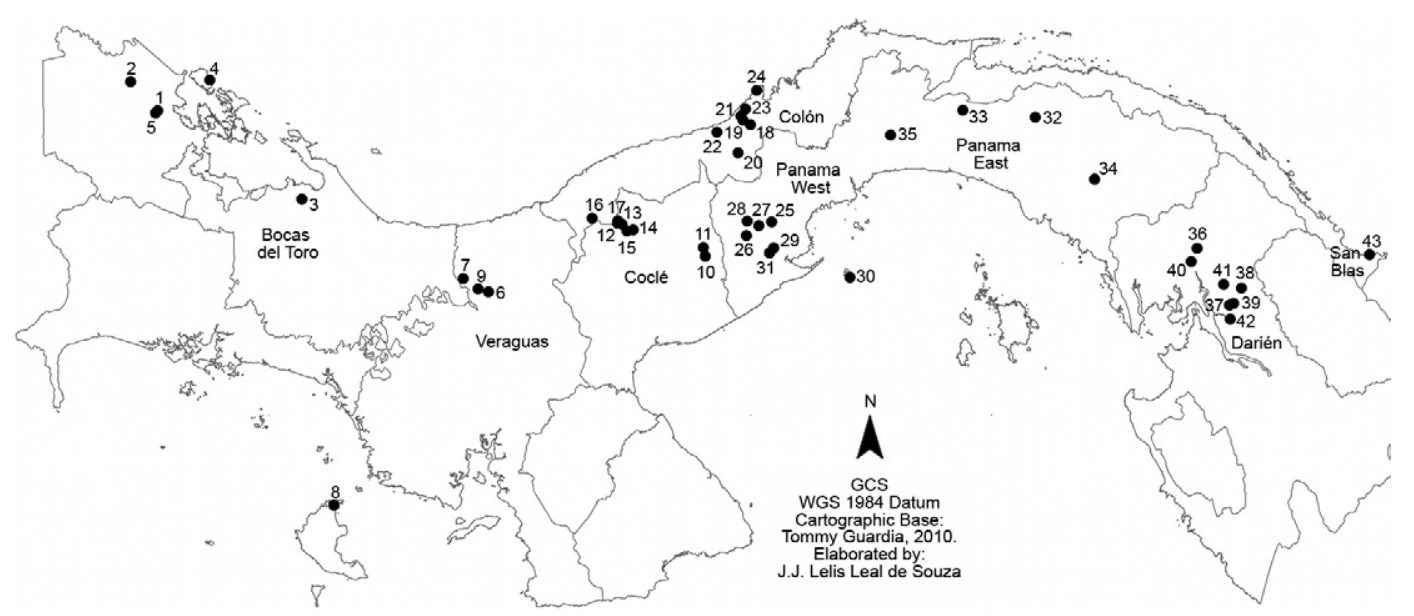

Fig. 1: geographical distribution of locations (see Table I) sampled of phlebotomine sandflies, vectors of American cutaneous leishmaniasis in Panama. 
tory data (simple correspondence analysis) was tested to evaluate the association of the species with the characteristic landscape. In this analysis, only anthropophilic sandfly species were considered as ACL vectors in Panama (Herrer et al. 1971, Tesh et al. 1971, Herrer \& Christensen 1973). Furthermore, other index of diversity $\left(\mathrm{H}^{\prime}\right)$ and dominance (D) (= $\Sigma$ pi2) were conducted and Sørensen's similarity index (Is) $(=2 \mathrm{c} / \mathrm{a}+\mathrm{b})$ (Magurran 1988) was calculated to define the differences between the three landscapes.

\section{RESULTS}

A total of 1,923 sandflies of the Lutzomyia genus were captured. Of these, $66.2 \%$ were anthropophilic species and vectors of Leishmania species in Panamá: Lu. panamensis $24.2 \%$, Lu. gomezi $18.6 \%$, Lu. trapidoi $15.6 \%$, Lutzomyia ovallesi $3 \%$, Lu. sanguinaria $1.5 \%$, Lu. olmeca bicolor $1.2 \%$, Lu. ylephiletor $0.9 \%$ and Lutzomyia carrerai $0.6 \%$. The other $33.8 \%$ of sandflies captured were zoophilic species: Lutzomyia triramula 3.2\%, Lutzomyia dysponeta $10.5 \%$, Lutzomyia camposi $6.8 \%$, Lutzomyia vesicifera $2.7 \%$, Lutzomyia sordellii $0.5 \%$, Lutzomyia vespertilionis $0.2 \%$, Lutzomyia carpenteri $1.3 \%$, Lutzomyia serrana $0.6 \%$, Lutzomyia gorbitzi $0.3 \%$, Lutzomyia aclydifera $4.2 \%$, Lutzomyia trinidadensis $2 \%$, Lutzomyia cruciata $0.5 \%$, Lutzomyia odax $0.5 \%$ and Lutzomyia barretoi $0.6 \%$, all of which are not responsible for transmitting the disease to humans as they are part of the wildlife cycle of leishmaniasis. Lutzomyia longipalpis, the main vector of visceral leishmaniasis, also was collected in two localities, Limón and in Boná Island.

A detailed analysis of the anthropophilic species per location is shown in Table I. Lu. gomezi, Lu. panamensis and $L u$. trapidoi were wide-spread and present in 35, 27 and 26 out of the 43 locations sampled, respectively, and were the most predominant species at 15,13 and seven of the locations, respectively. In contrast, $L u$. sanguinaria, Lu. olmeca bicolor and Lu. ylephiletor were scarce and found at a small subset of locations. Lu. ovallesi is the most common vector of $L$. braziliensis in Venezuela and Guatemala, and although it contributed only a small percentage to the total number of sandflies captured, it was the predominant species identified at two locations in the Darién and in Ollas Arriba (provinces of Panama). Lu. carrerai was collected only in Charagre, in Bocas de Toro; information for this species not is shown in Table I because it was isolated in low numbers and at few locations. Nine specimens of Lu. aclydifera and six of $L u$. $d y$ sponeta were captured in the Parque Altos de Campana.

The male to female ratio of captured sandflies was highest in Puerto Obaldía, El Llanillo and Unión Piña. In the other locations, more females than males were collected (Table I). Cutevilla, Vaquilla, Chirigui Arriba, Donoso, Piña and Ollas Arriba had high numbers of females ( $>50)$ and only one male was isolated in Arimay.

Cutevilla, Chirigui Arriba, Vaquilla and Piña yielded the highest relative abundance of anthrophilic sandflies (0.11, 0.09, 0.06 and 0.06 , respectively). The abundance of anthrophilic sandflies at the other locations varied from 0.004-0.052. Parque Altos de Campana was the only locality where no vector species was collected. In
$35 \%$ of the sites sampled, the Shannon-Weiner H' varied from $1.03-1.49$ and, in $42 \%$ of the sites, this index varied from 0.30-0.96 (Table I).

The number of cases of leishmaniasis registered in 2009 in the regions sampled is shown in Table I. Bocas del Toro, Colón and Coclé experienced the highest rates of leishmaniasis incidence, while the San Blas regions had the lowest incidence of leishmaniasis. Temperature, precipitation and humidity data are shown in Table I.

The abundance of $L u$. panamensis, Lu. gomezi and Lu. trapidoi varied significantly between the three types of environments $(\mathrm{p}<0.05)$. This difference, however, was not verified for $L u$. ylephiletor, $L u$. sanguinaria, $L u$. olmeca bicolor, Lu. ovallesi, Lu. carrerai and Lu. longipalpis (Table II).

The analysis of simple correspondence between the species and the type of environment showed a strong association of $L u$. gomezi and $L u$. trapidoi with fragmented environments. Lu. olmeca bicolor, Lu. panamensis and $\mathrm{Lu}$. ylephiletor were most strongly associated with forest environments and $L u$. sanguinaria, Lu. ovallesi, Lu. carrerai and Lu. longipalpis did not show any association with any type of environment $\left(\chi^{2}: 177,761 ; \mathrm{df}=16 ; \mathrm{p}<0,05\right)$ (Fig. 2).

When the species diversity at each type of landscape was examined, the Shannon-Weiner index showed that the rural environments contained a higher diversity $\left(\mathrm{H}^{\prime}=1.51\right)$ than the areas with fragmented vegetation $\left(\mathrm{H}^{\prime}=1.47\right)$ and the forested areas $\left(H^{\prime}=1.29\right)$. The Simpson index, in turn, showed that forest environments $(D=0.35)$ frequently had one dominant species, contrary to our observations in the fragmented $(\mathrm{D}=0.27)$ and rural environments $(\mathrm{D}=0.25)$. When the zoophilic species were included in the analysis, diversity was higher in the forest environments $\left(\mathrm{H}^{\prime}=2.41\right)$ than fragmented vegetation $\left(\mathrm{H}^{\prime}=2.01\right)$ and rural environments $\left(\mathrm{H}^{\prime}=1.99\right)$. We also observed that the Simpson index showed higher dominance in fragmented environments $(D=0.20)$, in rural environments $(\mathrm{D}=0.18)$ and in forest environments $(\mathrm{D}=0.12)$, contrary to the results with only anthrophilic vector species.

The similarity in sandfly species was $68.4 \%$ between the forest and rural environments; $55.7 \%$ between the rural and fragmented environments and $43.9 \%$ between the fragmented and forest environments. When zoophilic species are included, the similarity between rural and fragmented environments reached $57.1 \%$.

\section{DISCUSSION}

There are 7,476,836 ha of land in Panama. Of these, $43.36 \%$ are still covered by forest, but $33,531.61$ ha are destroyed every year by human activity (ANAM 2009). This loss in vegetation results in the migration and adaptation of some vector species to degraded environments, increasing their spatial distribution (Service 1991, Walsh et al. 1993, Grillet 2000, Aguiar \& Medeiros 2003).

The data obtained in this study shows the impact of human activity and deforestation on $\mathrm{Lu}$. gomezi, $\mathrm{Lu}$. panamensis and $L u$. trapidoi, abundant species with wide distributions in Panama. Earlier studies on sandflies reported the presence of these species in areas with leishmaniasis outbreaks, but showed that their geographical 


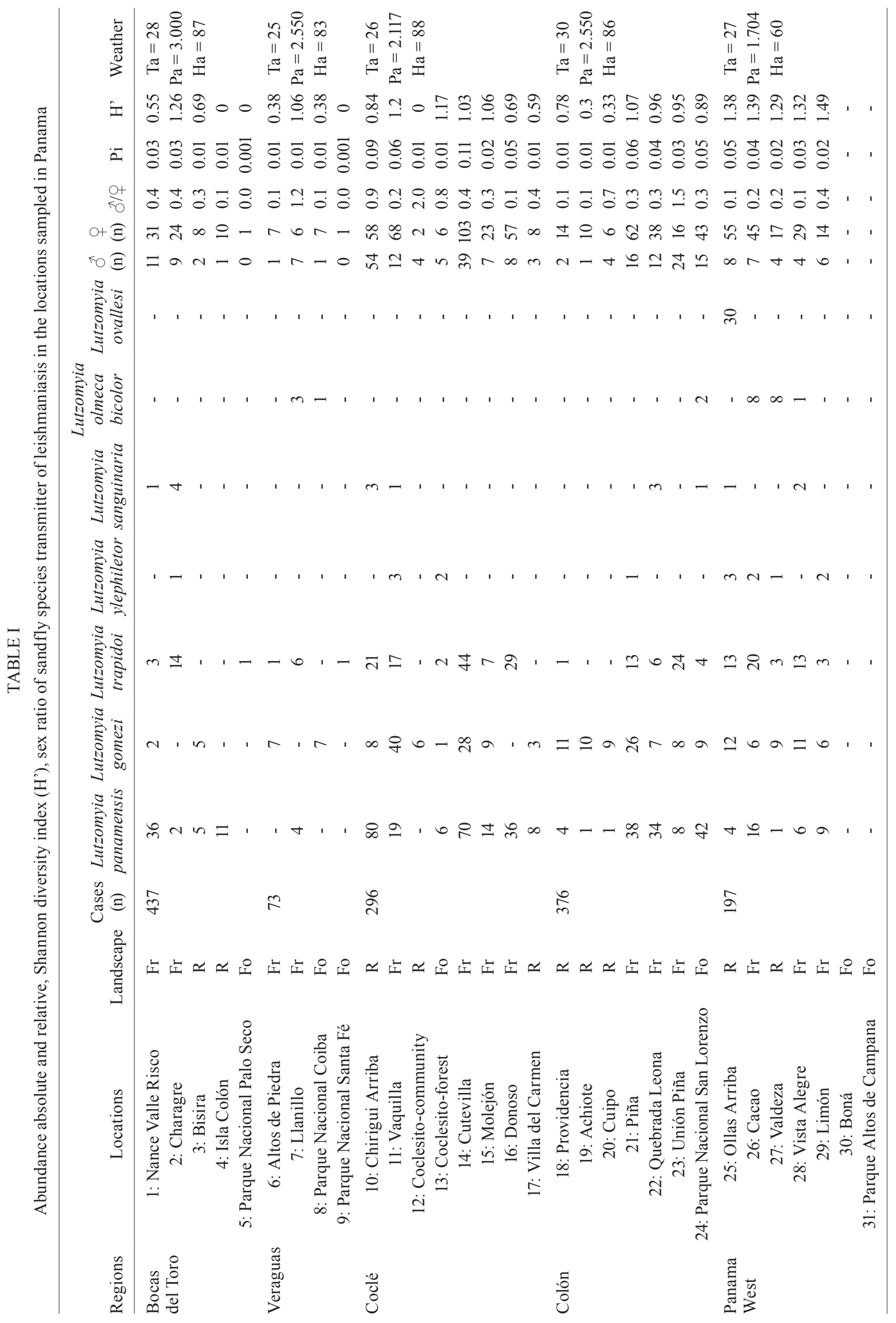




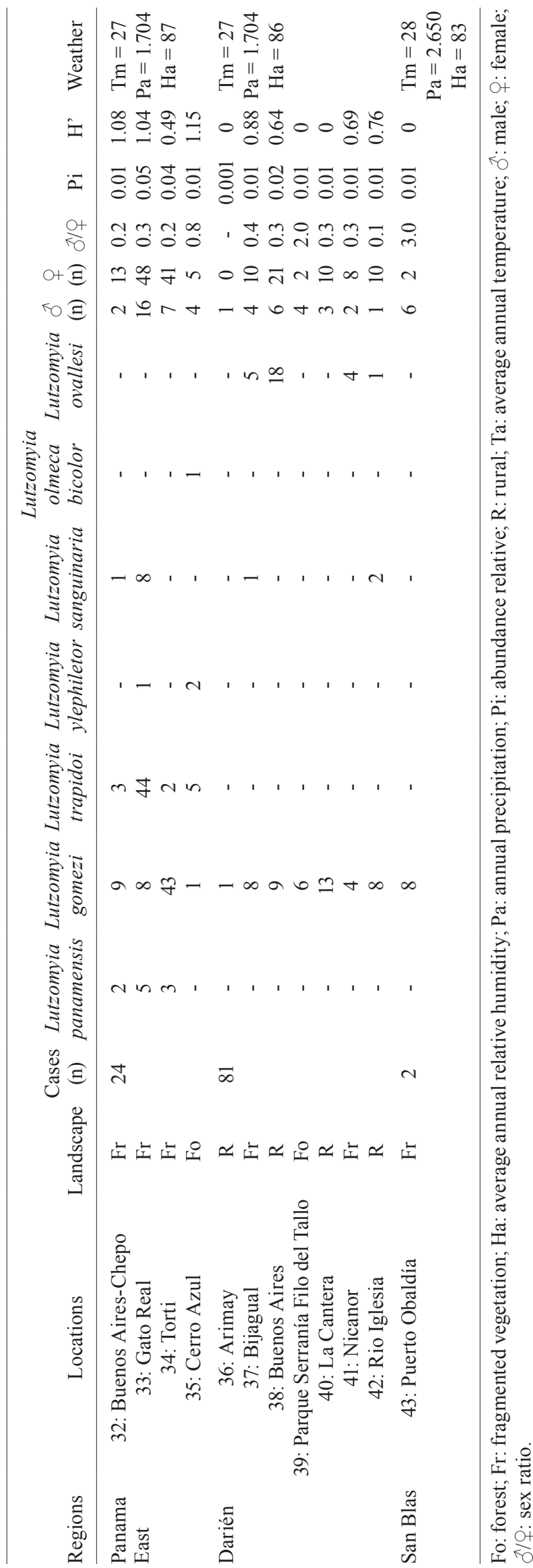

distributions were restricted to high-humidity forest regions (Chaniotis et al. 1971a, Rutledge \& Ellenwood 1975, Christensen et al. 1983). However, locations with recent outbreaks have been impacted by deforestation and there has also been an increase in the incidence of leishmaniasis in communities near the locations of the outbreaks.

The increase in leishmaniasis cases is due to a combination of multiple factors, involving changes in climate, human behaviours, vectors and reservoirs. The changing pattern of dispersal and the spatial distribution of sandflies to new locations are critical factors that may implicate an increased risk of human-vector contact. There are few similar studies that estimate the expansion of the vector species, but there are records from studies at the Gorgas Memorial Institute that were performed in the 1960-1980s that help us understand how the species distribution has changed. More current information could be used to alert health officials to what areas may be at risk for leishmaniasis and could help them evaluate what kind of intervention may be useful in those areas.

We observed that some species, such as $L u$. sanguinaria, Lu. ovallesi, Lu. olmeca bicolor, Lu. ylephiletor, $\mathrm{Lu}$. carrerai and $\mathrm{Lu}$. longipalpis, exhibited a discontinuous distribution, i.e., they were identified in localities far from each other. It is probable, however, that these species are also present in the intermediate regions between the points where they were collected. Therefore, deforestation could also be contributing to the expansion of the geographic distribution of these species. A more intensive sampling and comparative data in the surrounding regions could be used to test this hypothesis.

Climatic variations, high humidity and the prolonged rainy season in Panama have fundamental roles in maintaining the diversity of habitats available to sandflies (Chaniotis et al. 1971a, Christensen et al. 1983). The destruction of the forest and sandfly habitats permits the establishment of vector species in fragmented zones, close to peridomestic zones. In the provinces of Panama, Bocas del Toro, Colón and Veraguas, the sampling locations are subjected to rain throughout most of the year, while the wet and dry periods in other regions are clearly defined. The overall temperature varies by two degrees between regions. We did not examine the link between climate variables and species diversity in this study because of the high variability in climate throughout the day and between days. However, we may consider performing a further analysis of variations in climate and sandfly abundance over time in order to observe temporal distribution patterns and ecological niches.

As observed in the present study, the abundance of sandfly species was greater in locations with environments fragmented by human activities. Other authors have reported that $\mathrm{Lu}$. longipalpis has a wide geographical distribution (Souza et al. 2009) and is abundant in anthropic environments (Oliveira et al. 2006). Other species, such as Lutzomyia withmani, Lutzomyia evansi, Lutzomyia neivai and Lutzomyia olmeca olmeca, vectors of ACL agents in different regions of Latin America, are also abundant in degraded areas or those that have been altered by agriculture and cattle (Travi et al. 2002, Andrade Filho et al. 2007, Salomón et al. 2008, Virgens et al. 
2008, Pech-May et al. 2010). Therefore, it has been suggested that the creation of new habitats (stables, chicken ranges, orchards etc.), new food sources and the accumulation of organic material from domestic animals, in addition to the conditions of microclimates (temperature and humidity) of these ecotopes, favour the life cycle of sandflies and support their population growth in these habitats (Souza et al. 1999, Dias et al. 2003, Muniz et al. 2006, Monteiro et al. 2008).

The sex ratio analysis suggests that females are more prevalent than males in almost all locations. This is very important in terms of the population ecology because the growth and fitness of the sandfly population depends on the number of females. The estimated sex ratio should be considered when studying the best methods for efficient control of the sandfly population.

The diversity calculated for each individual location was low, especially considering that the values for the Shannon-Weiner index varied from 0-5. However, the results obtained in $35 \%$ of the locations indicated a remarkable coexistence of several vector species in different locations. A high diversity was also observed in rural and fragmented locations while a greater dominance was observed in the forest, indicating the prevalence of a single species in this type of environment.

When zoophilic species are included in the analysis, we observed an increase of diversity in the forest environment, greater dominance in the fragmented environment and similarities between the rural and fragmented environments. This may be because Lu. camposi and Lu. dysponeta were more abundant in those environments and therefore affected the weighting of the index. Based on our experimental design, we cannot say if these two species or other zoophilic species could be involved in transmission of leishmaniasis. Further research into the vector competence and anthropophily rates of these species is required in order to determine if they participate

\section{TABLE II}

Comparison mean of sandfly vector trapped in three different characteristic landscapes in Panama,January-June 2010

\begin{tabular}{lccc}
\hline & \multicolumn{3}{c}{ Landscape } \\
\cline { 2 - 4 } Species & Forest & Fragmented & Rural \\
\hline Lutzomyia panamensis $^{c}$ & $0.93^{b}$ & $2.27^{a}$ & $1.11^{b}$ \\
Lutzomyia gomezi $^{c}$ & $0.27^{b}$ & $1.59^{a}$ & $0.93^{a}$ \\
Lutzomyia trapidoi $^{c}$ & $0.47^{b}$ & $1.98^{a}$ & $0.41^{b}$ \\
Lutzomyia ylephiletor & 0.04 & 0.09 & 0.04 \\
Lutzomyia sanguinaria $_{\text {Lutzomyia olmeca bicolor }}$ & 0.01 & 0.21 & 0.04 \\
Lutzomyia ovallesi & 0.04 & 0.1 & 0.09 \\
Lutzomyia carrerai & 0 & 0.05 & 0.54 \\
Lutzomyia longipalpis & 0 & 0.13 & 0 \\
\hline
\end{tabular}

$a, b$ : distinct letters on the same line indicate significant differences in multiple comparison (alpha: 0.05); $c$ : significant differences in Kruskal Wallis test (alpha: 0.05). in the epidemiology of the disease. We have not found any reports of visceral leishmaniasis despite the presence of $\mathrm{Lu}$. longipalpis found in the community of Limon; the isolation of Lu. longipalpis is interesting because little is known about this species in Panama. We also did not find any reports of visceral leishmaniasis related to cases of cutaneous leishmaniasis.

Sandfly species, especially those that transmit leishmaniasis, have a high tendency to dominate degraded environments despite microclimatic changes, demonstrating their ability to adapt (Peterson \& Shaw 2003). The data on diversity and dominance of species in fragmented and rural environments of Panama obtained in this study suggest that these sandfly species are in the process of adapting to the gradual changes in landscape.

Therefore, human activities had a positive effect on vector species for leishmaniasis in Panama. Considering that there is no information on the diversity of sandflies in Panama prior to forest fragmentation, the results obtained in this study may serve as a baseline for future monitoring of the effects of the changing environment on the incidence of ACL in Panama.

Because the frequency of Lu. panamensis, Lu. gomezi and $L u$. trapidoi varies between the different types of environment, it seems likely that the reduction and fragmentation of forested landscapes influence the abundance and the composition of sandfly species. These changes in the sandfly species could be due to migration from forested to fragmented environments or through the adaptation of sandflies to new habitats. Additionally, the association of Lu. gomezi and Lu. trapidoi with fragmented environments suggests that these species may be better able to adapt to environmental alterations. The association of Lu. panamensis, Lu. olmeca bicolor and Lu. ylephiletor with the forested landscapes indicates that these species may prefer the conditions of this environment.

In conclusion, multiple factors affect the distribution, abundance and diversity of sandflies. Fragmentation of forests due to increased agricultural activity in Panama may be influencing the geographic distribution of three species of sandflies that are vectors of ACL agents in the country

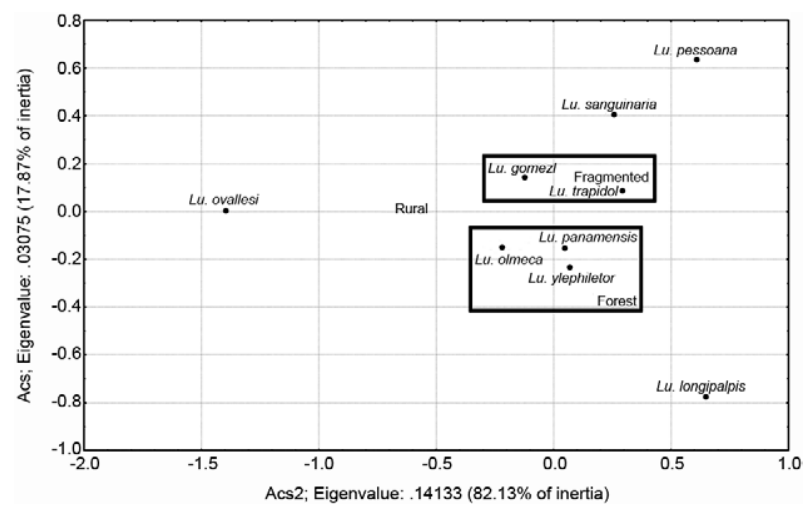

Fig. 2: simple correspondence plot showing the association of number of sandfly vector species (.) trapped for each characteristic landscape (forest, fragmented, rural) in Panama. Acs: analyses correspondence simple. 
(Lu. panamensis, Lu. gomezi and Lu. trapidoi). Analysis of species abundance and diversity showed that more than one vector species is often present in rural and fragmented locations where there have been cases of leishmaniasis. Although there is an absence of historical data that would allow us to compare the past and present sandfly populations in a quantitative manner, this study allows us to describe the current sandfly population and will enable us to evaluate the long-term effects of deforestation on the sandfly population and transmission of leishmaniasis.

\section{ACKNOWLEDGEMENTS}

To SENACYT, Instituto Commemorativo Gorgas ICGES and Smithsonian Tropical Research Institute, for logistic support in the collection of sandflies in Panama, to the assistant Yajaíra Perez Alvarez, for her help in field and lab work, to Roberto Rojas, for sort of specimens, to Prof Dr Paulo Roberto Cecon (UFV), for the review statistical analyses, and to José J Lelis Leal de Souza, for his help in the map.

\section{REFERENCES}

Aguiar GM, Medeiros WM 2003. Distribuição regional e hábitats das espécies de flebotomíneos do Brasil. In EF Rangel, R Lainson, Flebotomíneos do Brasil, Fiocruz Rio de Janeiro, p. 207-255.

ANAM - Autoridad Nacional del Ambiente 2000. Primer informe de la riqueza y estado de la biodiversidad de Panamá, ANAM, Panamá, 174 pp.

ANAM - Autoridad Nacional del Ambiente 2009. Informe del Estado del ambiente, ANAM, Panamá, 155 p.

Andrade Filho JD, Galati EAB, Falcão AL 2007. Nyssomyia intermedia (Lutz \& Neiva, 1912) and Nyssomyia neivai (Pinto, 1926) (Diptera: Psychodidae: Phlebotominae) geographical distribution and epidemiological importance. Mem Inst Oswaldo Cruz 102: 481-487.

Azpurua J, de la Cruz D, Valderrama A, Windsor D 2010. Lutzomyia sandfly diversity and rates of infection by Wolbachia and an exotic Leishmania species on Barro Colorado Island, Panama. PLoS Negl Trop Dis 4: e627.

Carvalho GML, Falcão AL, Andrade Filho JD 2006. Taxonomic revision of phlebotomine sandfly species in the series davisi and panamensis of the subgenus Psychodopygus Mangabeira, 1941 (Diptera: Psychodidae: Phlebotominae). Mem Inst Oswaldo Cruz 101: 129-136.

Chaniotis BN, Correa MA, Tesh RB, Jonhson KM 1971a. Daily and seasonal man-biting activity of Phlebotominae sandflies in Panama. J Med Entomol 8: 415-420.

Christensen H 1972. Check list of the Phlebotominae sandflies (Diptera: Psychodidae) of Panama including two species not previously reported. Mosq News 32: 89.

Christensen H, Fairchild GB, Herrer A, Johnson C, Young D, de Vásquez A 1983. The ecology of cutaneous, leishmaniasis in the Republic of Panama. J Med Entomol 20: 463-484.

Christensen H, Johnson C, Vasquez AM 1984. Leishmaniasis cutánea en Panamá: un breve resumen. Rev Med Panama 9: 182-1987.

Christensen HA, Herrer A, Telford SR 1972. Enzootic cutaneous leishmaniasis in eastern Panama. II. Entomological investigations. Ann Trop Med Parasitol 66: 55-66.

Dias FO, Lorosa ES, Rebêlo JM 2003. Blood feending sources and peridomiciliation of Lutzomyia longipalpis (Lutz \& Neiva, 1912) (Psychodidae, Phlebotominae). Cad Saude Publ 19: 1373-1380.

Grillet ME 2000. Factors associated with distribution of Anopheles aquasalis and Anopheles oswaldoi (Diptera: Culicidae) in a malarious area, northeastern Venezuela. J Med Entomol 37: 231-238.

Herrer A 1971. Leishmania hertigi sp.n. from the tropical porcu-spine, Coendou rothschildi. J Parasitol 57: 626-629.

Herrer A, Christensen HA 1973. Epidemiological patterns of cutaneous leishmaniasis in Panama. Am J Trop Med Hyg 25: 54-58.

Herrer A, Christensen HA 1976. Natural cutaneous leishmaniasis among dogs in Panama. Am J Trop Med Hyg 25: 59-63.

Herrer A, Telford S, Christensen HA 1971. Enzootic cutaneous leishmaniasis in eastern Panama I: investigation of the infection among forest mammals. Ann Trop Med Parasitol 65: 349-358.

Jiménez AE, Rojas JC, Vargas F, Herrero MV 2000. Temporal and spatial variation of phlebotomine (Diptera: Psychodidae) community diversity in a cutaneous leishmaniasis endemic area of Costa Rica. J Med Entomol 37: 216-221.

Magurran AE 1988. Ecological diversity and its measurement, Princeton University Press, Princeton, 179 pp.

Méndez E 1999. Insectos y otros artrópodos de importancia médica y veterinaria, Impresora Pacífico, Panama, 45 pp.

MINSA - Ministerio de Salud del Perú 2005. Situación Nacional de Salud, Dirección Nacional de Politicas de Salud, MINSA, Lima, 57 pp.

Miranda A, Carrasco R, Paz H, Pascale JM, Samudio F, Saldaña A, Santamaría G, Mendoza Y, Calzada J 2009. Molecular epidemiology of American tegumentary leishmaniasis in Panama. Am J Trop Med Hyg 81: 565-571.

Monteiro WM, Neitzke HC, Lonardoni MV, Silveira TG, Ferreira ME, Teodoro U 2008. Distribuição geográfica e características epidemiológicas da leishmaniose tegumentar americana em áreas de colonização antiga do estado do Paraná, sul do Brasil. Cad Saude Publ 24: 1291-1303.

Muniz LHG, Rossi RM, Nietzke HC, Monteiro WM, Teodoro U 2006. Estudo dos hábitos alimentares de flebotomíneos em área rural no sul do Brasil. Rev Saude Publ 19: 1087-1093.

Oliveira AG, Galati EAB, Oliveira O, Oliveira GR, Espindola IAC, Dorval MEC, Brazil RP 2006. Abundance of Lutzomyia longipalpis (Diptera: Psychodidae: Phlebotominae) and urban transmission of visceral leishmaniasis in Campo Grande, state of Mato Grosso do Sul, Brazil. Mem Inst Oswaldo Cruz 101: 869-874.

Pech-May A, Escobedo-Ortegón FJ, Berzunza-Cruz M, RebollarTéllez EA 2010. Incrimination of four sandfly species previously unrecognized as vectors of Leishmania parasites in Mexico. Med Vet Entomol 24: 150-161.

Peterson AT, Shaw JJ 2003. Lutzomyia vectors for cutaneous leishmaniasis in southern Brazil: ecological niche models, predicted geographic distributions and climate change effects. Int J Parasitol 33: 919-931.

Rutledge LC, Ellenwood DA 1975. Production of Phlebotominae sandflies on the open forest floor in Panama: phytologic and edaphic relations. Environm Entomol 4: 83-89.

Salomón OD, Quintana MG, Zaidenberg M 2008. Urban distribution of Phlebotominae in a cutaneous leishmaniasis focus, Argentina. Mem Inst Oswaldo Cruz 103: 282-287.

Seccombe AK, Ready PD, Huddleston LM 1993. A catalogue of Old World Phlebotominae sandflies (Diptera: Psychodidae: Phlebotominae), The Natural History Museum, London, $57 \mathrm{pp}$.

Service MW 1991. Agricultural development and arthropod-borne diseases: a review. Rev Saude Publ 25: 165-178. 
Souza GD, Santos E, Andrade Filho JD 2009. The first report of the main vector of visceral leishmaniasis in America, Lutzomyia longipalpis (Lutz \& Neiva) (Diptera: Psychodidae: Phlebotominae), in the state of Rio Grande do Sul, Brazil. Mem Inst Oswaldo Cruz 104: 1181-1182.

Souza RN, Lima JWO, Souza FV, Gadelha AC, Braga VSS 1999. Estabelecimento de um criadouro natural de Lutzomyia longipalpis. Rev Soc Bras Med Trop 32: 214-215.

Sudia WD, Chamberlain RW 1962. Battery operated light trap, an improved model. Mosq News 22: 126-129.

Tesh RB, Chaniotis BN, Aronson MD, Johnson KM 1971. Natural host preferences of Panamanian Phlebotominae sandflies as determined by precipitin test. Am J Trop Med Hyg 20: 150-156.

Travi BL, Alder GH, Lozano M, Cadena H, Montoya-Lerma J 2002. Impact of habitat degradation on Phlebotominae (Diptera: Psy- chodidae) of tropical dry forest in northern Colombia. J Med Entomol 39: 451-456.

Virgens TM, Santos CB, Pinto IS, Silva KS, Leal FC, Falqueto A 2008. Phlebotominae sandflies (Diptera: Psychodidae) in an American tegumentary leishmaniasis transmission area in northern Espírito Santo state, Brazil. Cad Saude Publ 24: 2969-2978.

Walsh JF, Molyneux DH, Birley MH 1993. Deforestation: effects on vector-borne disease. Parasitol 106: 55-75.

Young DG, Arias JA 1992. Flebótomos: vectores de leishmaniasis en las Américas, Technical Report 33, Organización Pan-Americana de Salud, Washington, 28 pp.

Young DG, Duncan MA 1994. Guide to the identification and geographic distribution of Lutzomyia sandflies in Mexico, the West Indies, Central and South America (Diptera: Psychodidae). Mem Amer Ent Inst 54: 1-881. 